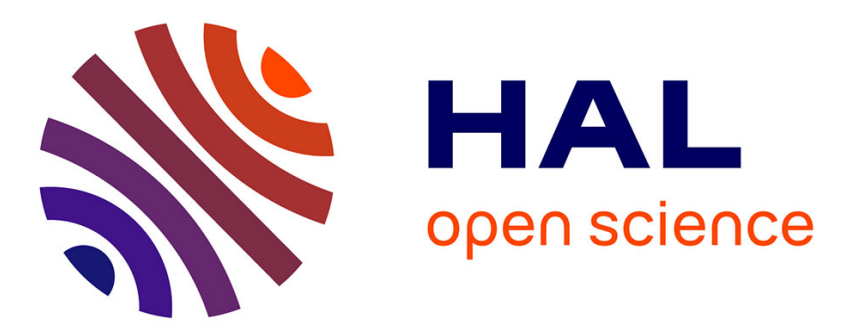

\title{
Is inequality harmful for the environment in a growing economy?
}

Hubert Kempf, Stéphane Rossignol

\section{To cite this version:}

Hubert Kempf, Stéphane Rossignol. Is inequality harmful for the environment in a growing economy?. 2006. halshs-00117046

\section{HAL Id: halshs-00117046 \\ https://shs.hal.science/halshs-00117046}

Submitted on 29 Nov 2006

HAL is a multi-disciplinary open access archive for the deposit and dissemination of scientific research documents, whether they are published or not. The documents may come from teaching and research institutions in France or abroad, or from public or private research centers.
L'archive ouverte pluridisciplinaire HAL, est destinée au dépôt et à la diffusion de documents scientifiques de niveau recherche, publiés ou non, émanant des établissements d'enseignement et de recherche français ou étrangers, des laboratoires publics ou privés. 


\section{Centre d'Economie de la Sorbonne}

UMR 8174

Is inequality harmful for the environment in a growing economy?

Hubert KEMPF

Stéphane RossignOL

2006.45
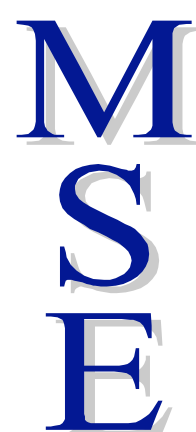

la

de

CENTRE NATIONAL

DE LARECHERCHE

SCENTIFIQUE 


\title{
Is inequality harmful for the environment in a growing economy? Revised version.
}

\author{
Hubert Kempf ${ }^{\sharp}$ \& Stéphane Rossignol ${ }^{\perp *}$ \\ \# Corresponding author. EUREQua, CNRS \\ and Université Paris-I, Panthéon-Sorbonne, \\ 106-112 Bd de l'Hopital, 75647 Paris Cedex 13, France. \\ kempf@univ-paris1.fr \\ ${ }^{\perp}$ Université de Versailles and EUREQua, CNRS.
}

September 23, 2005

\begin{abstract}
In this paper we investigate the relationship between inequality and the environment in a growing economy from a political economy perspective. We consider an endogenous growth economy, where growth generates pollution and a deterioration of the environment. Public expenditures may either be devoted to supporting growth or abating pollution. The decision over the public programs is done in a direct democracy, with simple majority rule. We prove that the median voter is decisive and show that inequality is harmful for the environment: the poorer the median voter relative to the average individual, the less she will tax and devote resources to the environment, preferring to support growth.
\end{abstract}

${ }^{*}$ We wish to thank participants to seminars in the University of Paris-1 Panthéon-Sorbonne, the T2M 2004 meeting, CORE, and especially Rabah Amir, Pierre Pestieau, Katrin Millock and Lionel Ragot for helpful comments on earlier drafts of this paper. The ideas expressed here and the remaining errors are of our own responsibility. 


\section{Introduction}

The distributive issue associated to the protection of the environment has been widely studied in the literature, mostly in relation with the so-called "Environmental Kuznets Curve". ${ }^{1}$ Empirically, Magnani (2000), using cross-section data, shows that there exists a negative relationship between inequality and public expenditures related to the protection of the environment. However, this issue has been studied by means of static models of the economy. But environmental problems are recognized to raise intertemporal tradeoffs and the concern over environmental protection policies must focus on the dynamic and long-term consequences of any measure. On the other hand, the relationship between growth and inequality has also been thoroughly studied (see the survey by Aghion, Caroli and Garcia-Penalosa, 1999) ${ }^{2}$ but these studies have neglected to include the interplay with environment issues.

The aim of this paper is to tackle the issue between inequality and environment protection in the context of a growing economy.$^{3}$ We do so adopting a political-economic perspective. ${ }^{4}$ Basically, we develop the following view: both the protection of the environment and the growth process, while potentially conflicting, are major public concerns in modern polities. In particular, environment protection depends on how much public resources to devote to it, rather than to other policies aimed at sustaining growth and consumption. As far as individuals are differenciated with respect to their capital endowment and more generally wealth, they hold conflicting views on the necessity to protect the environment, relative to the goal of sustaining growth. In other words, the inequality schedule (that is the initial distribution of capital among agents) shapes the distribution of opinions on the trade-off between growth and environment protection. Through voting, these opinions are aggregated and lead to a political decision on the allocation of resources to environment protection. Therefore, inequality impacts on the environment, even when agents do not differ in their preferences over physical consumption and the environment.

In the economy which we consider, it impacts negatively. Indeed, inequality is harmful

\footnotetext{
${ }^{1}$ See among recent references, Andreoni and Levinson (2001), Magnani (2000) and Torras and Boyce (1998). For a general survey on environment and growth, see Smulders (1999).

${ }^{2}$ Empirical studies on this issue lead to conflicting views: Perotti (1996) concluded that cross-country studies lead to a negative relationship. Later on, panel estimations lead to a positive relationship.

${ }^{3}$ Magnani (2000) refers to growth as the factor behind different levels of aggregate output but she does not model the growth process and therefore does not tackle the intertemporal trade-off raised by environmental policy, that is its impact on the saving decision. Marsiliani and Renström (2000) address this issue using an overlapping generations model, but they skip difficult questions related to the timeconsistency of the political decisions. Jones and Manuelli (2001) also use an overlapping generations model to tackle the relationship between pollution and growth in a political setting, but they do not refer to inequality as the source of conflicts of interest among voters; they instead assume that the old generation has the power to choose.

${ }^{4}$ That political institutions matter in the understanding of the relationship between environment and growth is well illustrated by Earnhart (1997), comparing environment protection policies under communism and democracy.
} 
to the environment: the more unequal a society (in a sense which will be made more precise below), the more resources will be used to sustain growth despite its negative impact on the state of the environment. ${ }^{5}$ As a result, there is an inverse relationship between the concern for the environment and the growth rate chosen by the polity. We consider a growing economy with two central features. First, public expenditures contribute to growth, as in a AK endogenous growth model with productive public good. Second, aggregate production pollutes and deteriorates the state of the environment in a way which is detrimental to any one's utility since the environment is a pure public good in this economy. However, an active public policy is able to improve the environment: by devoting public resources to the protection of the environment, the government can fight off the adverse effects of growth on the environment. This obviously raises a public dilemma: how much resources to devote to the adverse goals of growth and environment protection?

The solution to this dilemma depends on how much the polity values the quality of its environment relative to its material well-being linked to consumption of physical goods. Assuming identical utility functions the arguments of which are the state of the environment and physical consumption, each agent in this economy views this trade-off according to her own wealth. ${ }^{6}$ We find that the wealthier (relative to the mean initial capital endowment) an agent, the more she is in favor of taxation, in particular for the sake of depollution activities. This suggests that inequality matters a lot for the solution to this trade-off. In other words, there are conflicting views among individuals and the trade-off facing the entire polity can only be solved by means of a political decision. ${ }^{7}$

The quality of the environment is a pure public good. This may justify the use of public spending for environment improvement. On the other hand, when public resources are used to productive purposes, it uplifts the productivity of capital and labor, hence their marginal remunerations, in any period and thus, it increases the rate of growth. The marginal benefits of growth-enhancing public spending are larger, the poorer an agent is. A poorer agent faces a steeper trade-off between a marginal improvement of the environment and a marginal reduction in consumption. On the whole, standard economic and environmental issues are related and linked to inequality as agents with different endowments perceive differently this trade-off.

\footnotetext{
${ }^{5}$ Admittedly, the relationship between pollution and growth is not simple to assess. There are many types of pollutants and many sources of growth, including R\&D which may lead to the use of more environment-friendly technologies. However what we have in mind is the debate on global warming. There is much evidence that the man-made industrialization process leads to a significant increase in $\mathrm{CO}_{2}$ emissions, adversely affecting world climate and welfare. See for example Holtz-Eakin and Selden (1995).

${ }^{6}$ That is, contrary to Magnani (2000), we do not assume that wealthier agents are characterized by a larger weight given to the state of the environment.

${ }^{7}$ Empirical studies support this view. Kahn and Matsusaka (1997) show that the environment is found to be a normal good for most people, except those with very high incomes. They stress that income and price can explain most of the variation in voting; there is little need to introduce "preference" variables such as political ideology.
} 
Applying the majority decision making rule to the political resolution of the tradeoff we have just mentioned, readily leads us to our conclusion. The poorer the median voter, the more she cares about material well-being, the more she is willing to channel public resources to the sustaining of growth and the less she will devote resources to the restoration of the environment altered by economic growth. ${ }^{8}$ The more unequal a society, for a given amount of initial wealth, the more resources will be devoted to the upholding of growth and therefore the more degraded will be the environment. ${ }^{9}$

In the next section, we develop the model of a growing economy with environment. In section 3 , we address the political decision to be taken over the protection of the environment. The last section concludes.

\section{The model}

In this section, we set up the model of an economy where growth has an adverse influence on the environment. Pollution is a direct consequence of production ${ }^{10}$ and public resources can either sustain growth or improve the environment. Infinitely lived agents care both about their consumption profile and the state of the environment over time.

Individuals differ in their initial endowment of capital. The political decision about taxation and spending is taken at the beginning of time according to a simple majority rule. The public budget is balanced at each period. Hence, the polity has to make a joint decision about the tax rate and the split of public receipts into growth-enhancing and environment-linked spending. This decision is irrevocable, made before any capital accumulation decision and will be applied at each period. When this decision is reached, each individual acts as an intertemporal utility-maximizer, taking the public decision as given and decides about her intertemporal saving schedule.

\subsection{Production}

The production function is similar to that of Alesina and Rodrik (1994), which is adapted from Barro (1990). A public good $G_{Y}$ is produced by government and contributes to production in addition to capital and labor. The aggregate production function is

$$
Y=A K^{\alpha}\left(G_{Y}\right)^{1-\alpha} L^{1-\alpha}
$$

\footnotetext{
${ }^{8}$ In this paper, when we refer to "poorer" or "wealthier" agents, it is based on their initial endowment, and relative to the average initial endowment. That is why we stress inequality rather than (absolute) poverty.

${ }^{9}$ So this paper is related to the literature on the political economy of redistribution (See Roberts, 1977, and Meltzer and Richards, 1981). Some papers have cast the issue of redistribution within an endogenous growth model (see Alesina and Rodrik, 1994, Fiaschi, 1999, Kempf and Rossignol, 2005). Here we use a similar framework to address the trade-off between growth and environment protection.

${ }^{10}$ Alternatively, pollution could be linked to consumption expenditures. In our balanced-growth model with no transition to the steady-state, this does not entail any major difference.
} 
where $K$ represents aggregate capital and $L$ aggregate labor. The factors are remunerated at their marginal productivity:

$$
r=\frac{\partial Y}{\partial K}=\frac{\alpha Y}{K} \text { and } \widehat{w}=\frac{\partial Y}{\partial L}=\frac{(1-\alpha) Y}{L}
$$

then $r K+\widehat{w} L=\alpha Y+(1-\alpha) Y=Y$.

There are $\mathrm{N}$ agents in the economy ( $N$ odd). At time 0 , each agent is endowed with a given quantity of initial capital $k_{i}(0)$, and $k_{i}(0) \neq k_{j}(0)$, for any $i \neq j$. There are no two identical endowments. Without loss of generality, we rank individuals according to their endowments: $k_{i}(0)<k_{j}(0)$, for any $i<j$. An agent is characterized by a median initial capital endowment, denoted by $k_{m}$.

The total public spending is $G=G_{Y}+G_{E}$, where $G_{Y}$ represents the public spending contributing to production, and $G_{E}$ the amount of public spending against pollution. The product is taxed to finance public spending: $G=\tau Y \cdot{ }^{11}$ We denote by $\tau_{Y}$ the part of the tax which finances $G_{Y}$, and $\tau_{E}$ the part of the tax which finances $G_{E}$. It means that $G_{Y}=\tau_{Y} Y$, and $G_{E}=\tau_{E} Y$. We denote by $\tau=\tau_{E}+\tau_{Y}$ the overall tax rate. We restrict $\tau \in(0,1)$ as the overall tax rate $\tau$ cannot be bigger than 1 . According to (1), the public good $G_{Y}$ cannot be negative, hence $\tau_{Y}>0 . \tau_{E}$ can be either positive or negative, which implies that $\tau_{E}>0$ corresponds to the case of a policy aiming at protecting the environment, $\tau_{E} \leq 0$ corresponds to the case where the environment is depleted for the sake of growth. Here, we focus on the former case. In brief, the public decision amounts to choosing a pair of tax rates $\left(\tau_{E}, \tau_{Y}\right)$. This pair will be applied at any period. ${ }^{12}$

Inserting the relation $G_{Y}=\tau_{Y} Y$ in equation (1), we get:

$$
Y=A K^{\alpha}\left(\tau_{Y} Y\right)^{1-\alpha} L^{1-\alpha}=A K^{\alpha}\left(\tau_{Y} L\right)^{1-\alpha} Y^{1-\alpha}
$$

which is equivalent to:

$$
Y=A^{1 / \alpha} K\left(\tau_{Y} L\right)^{(1-\alpha) / \alpha}
$$

We normalize labor $(L=1)$, thus:

$$
Y=A^{1 / \alpha} \tau_{Y}^{(1-\alpha) / \alpha} K
$$

Using (2), we get:

$$
r=\alpha A^{1 / \alpha} \tau_{Y}{ }^{(1-\alpha) / \alpha} \text { and } \widehat{w}=(1-\alpha) A^{1 / \alpha} \tau_{Y}{ }^{(1-\alpha) / \alpha} K .
$$

\footnotetext{
${ }^{11}$ Here we differ from Alesina-Rodrik who consider a tax based on capital.

${ }^{12}$ We shall discuss this assumption in section 3 .
} 


\subsection{Quality of environment}

We assume that the quality $E$ of the environment (with $E \geq 0$ ) is a decreasing function of the production $Y$ (because of negative externalities of the production), ${ }^{13}$ and an increasing function of the public spending against pollution $G_{E}$ :

$$
E=E\left(Y, G_{E}\right)
$$

$G_{E}$ and $Y$ are instantaneous values, that means for example that a quick increase of $G_{E}$ improves immediately $E$. In other words, we consider the pollution as a flow, and not as a stock (see Marrewijk et al., 1993).

We assume that $E$ is a homogeneous function of $Y$ and $G_{E}$. More precisely, $E$ is homogeneous of degree 0 , which means that $E$ is a function of the ratio $\frac{G_{E}}{Y}=\tau_{E}$. This homogeneity assumption means that growth is not the "ideal" solution of the environmental problems, neither ineluctably harmful for the environment. ${ }^{14}$ Hence we can write:

$$
E=E\left(\tau_{E}\right)
$$

\subsection{Individual utility function}

The instantaneous utility function of agent $i$ depends on her level of consumption $c_{i}$ and on the quality of the environment $E$ (which does not depend on the agent $i$ ), $E \geq 0$. We assume that this total utility is separable in the physical individual consumption $c_{i}$ and in the quality of the environment $E$, since there is no a priori interaction between these two aspects. It means in particular that it is not a product but a sum:

$$
U\left(c_{i}, E\right)=\ln \left(c_{i}\right)+\widetilde{V}(E) .
$$

Because of (8), we get:

$$
U\left(c_{i}, E\right)=\ln \left(c_{i}\right)+V\left(\tau_{E}\right)
$$

and we assume that the $V$ function is increasing and concave: $V^{\prime}>0$ and $V^{\prime \prime}<0$. An improvement in the environment improves utility at a decreasing pace. Despite the separability of this function, we will show that $c_{i}$ depends on $\tau_{E}$ (cf. (17)).

\footnotetext{
${ }^{13}$ For this reason, the environment appears as specific compared to more standard public goods, like national defense or education, which are not considered as directly adversely affected by the production process. $E$ equal to zero or negative amounts to an unsufferable environment.

${ }^{14}$ If $E$ is homogeneous of degree $\beta$, then (7) leads to

$$
\forall \mu>0, E\left(\mu Y, \mu G_{E}\right)=\mu^{\beta} E\left(Y, G_{E}\right)
$$

1. If $\beta>0$, when we multiply $Y$ and $G_{E}$ by a factor $\mu>1$, then the quality of the environment is increased by a factor $\mu^{\beta}$. In particular growth will automatically increase $E$. We will tend to ecological heavens.

2. If $\beta<0$, when we multiply $Y$ and $G_{E}$ by a factor $\mu>1$, then the quality of the environment decreases. In particular the growth will automatically decrease $E$. We will tend to ecological hell.

To sum up, if $\beta>0$, any action is useless since the economic growth will solve the ecological problems, and if $\beta<0$, the growth must be stopped because an indefinite growth would ineluctably harm the environment.
} 


\subsection{Accumulation decisions and growth}

When deciding about saving, an individual takes as given and constant over time the pair of tax rates. Given (6), the net income of agent $i$ is:

$$
y_{i}=\left(r k_{i}+\widehat{w} l_{i}\right)(1-\tau)
$$

where $l_{i}$ is the inelastic labor supply of agent $i$, equal to $L / N=1 / N$.

The agent $i$ maximizes her intertemporal utility under budget constraint:

$$
\begin{aligned}
\max _{c_{i}} W^{i} & =\int_{0}^{+\infty} e^{-\rho t}\left[\ln \left(c_{i}(t)\right)+V\left(\tau_{E}\right)\right] d t \\
\text { such that } \dot{k}_{i} & =\left(r k_{i}+\widehat{w} l_{i}\right)(1-\tau)-c_{i} .
\end{aligned}
$$

Since the tax rate $\tau_{E}$ and the state of the environment $E$ are beyond the reach of agent $i$, the program of agent $i$ becomes:

$$
\begin{aligned}
\max _{c_{i}} W^{i} & =\int_{0}^{+\infty} e^{-\rho t} \ln \left(c_{i}(t)\right) d t \\
\text { such that } \dot{k}_{i} & =\left(r k_{i}+\widehat{w} l_{i}\right)(1-\tau)-c_{i} .
\end{aligned}
$$

The Hamiltonian of (13) is:

$$
\mathcal{H}=\ln \left(c_{i}(t)\right)+\lambda\left[\left(r k_{i}+\widehat{w} l_{i}\right)(1-\tau)-c_{i}\right]
$$

with $\frac{\partial \mathcal{H}}{\partial c_{i}}=\frac{1}{c_{i}}-\lambda$ and $\frac{\partial \mathcal{H}}{\partial k_{i}}=\lambda r(1-\tau)$.

The solution to (14) is:

$$
\begin{aligned}
\frac{\partial \mathcal{H}}{\partial c_{i}} & =0 \\
\text { and } \dot{\lambda} & =\rho \lambda-\frac{\partial \mathcal{H}}{\partial k_{i}}
\end{aligned}
$$

which leads to $\lambda=\frac{1}{c_{i}}$ and $\dot{\lambda}=\rho \lambda-\lambda r(1-\tau)$. Since $\frac{\dot{\lambda}}{\lambda}=-\frac{\dot{c}_{i}}{c_{i}}$, finally $\frac{\dot{c}_{i}}{c_{i}}=r(1-\tau)-\rho$ obtains.

We assume that we are on a balanced growth path, i.e. $\frac{\dot{c}_{i}}{c_{i}}=\frac{\dot{k}_{i}}{k_{i}}$. The growth rate $\eta$ is then given by:

$$
\eta=\frac{\dot{c}_{i}}{c_{i}}=\frac{\dot{k}_{i}}{k_{i}}=r(1-\tau)-\rho .
$$

Introducing this value in the budget constraint, we get:

$$
\dot{k}_{i}=\left(r k_{i}+\widehat{w} l_{i}\right)(1-\tau)-c_{i}
$$

and:

$$
\frac{\dot{k}_{i}}{k_{i}}=\frac{1}{k_{i}}\left(r k_{i}+\widehat{w} l_{i}\right)(1-\tau)-\frac{c_{i}}{k_{i}}
$$

Then:

$$
r(1-\tau)-\rho=\left(r+\widehat{w} \frac{l_{i}}{k_{i}}\right)(1-\tau)-\frac{c_{i}}{k_{i}} .
$$


We can note that $\widehat{w}=\omega K$, setting $\omega=(1-\alpha) A^{1 / \alpha} \tau_{Y}^{(1-\alpha) / \alpha}$. Equation (16) becomes:

$$
r(1-\tau)-\rho=\left(r+\omega \frac{K l_{i}}{k_{i}}\right)(1-\tau)-\frac{c_{i}}{k_{i}}
$$

which implies:

$$
\begin{aligned}
c_{i} & =\left[\left(r+\omega \frac{K l_{i}}{k_{i}}\right)(1-\tau)-r(1-\tau)+\rho\right] k_{i} \\
& =\left[\rho+\omega \frac{K l_{i}}{k_{i}}(1-\tau)\right] k_{i} .
\end{aligned}
$$

We denote by $\sigma_{i}=\frac{K l_{i}}{k_{i}}=\frac{\bar{k}}{k_{i}}$, the ratio of mean capital to the capital owned by agent $i$. The set of these ratios characterizes the inequality schedule of this economy. It is independent of the time since $l_{i}$ is constant, and $K$ and $k_{i}$ grow at the same rate $\eta$. This is an important property of this type of model: when tax rates remain constant over time, there is no modification of relative inequality between agents over time, even though each of them is getting richer.

The higher $\sigma_{i}$, the poorer agent $i$ relative to the average capital endowment. We can rewrite the previous equation as follows:

$$
c_{i}=\rho k_{i}+\omega(1-\tau) \bar{k}=\left[\rho+\omega \sigma_{i}(1-\tau)\right] k_{i} .
$$

This equation gives the optimal level of consumption of agent $i$, taking $\tau$ as given. $c_{i}$ is of course an increasing function of $k_{i}$ : the richer agent $i$, the higher her consumption. Also quite intuitively, the higher the total tax rate that she bears, the lower her consumption. Remark that the consumption/capital ratio is an increasing function of $\sigma_{i}$ : for a given overall tax rate $\tau$, the poorer an individual, the more she consumes relative to her endowment, that is the less she saves. This is in line with the result obtained by Alesina and Rodrik in their simpler model.

\section{The political economy of taxes and the environment}

As in Alesina and Rodrik, we impose that tax rates be constant over time and the political decision on the tax rates $\left(\tau_{Y}, \tau_{E}\right)$ be taken before the accumulation process starts. It is taken according to majority rule. The timing of the moves is as follows:

1. The endowment schedule $\left\{k_{i}(0)\right\}$ is determined;

2. The political decision is made, according to majority rule, simultaneously on $\tau_{Y}^{i}$ and $\tau_{E}^{i}$

3. Agents choose their saving plans. 
It is important to note that in the context of this model, these assumptions imply that the relative endowment of agents do not change and therefore the initial median voter retains this property forever. This ensures the time-consistency of the political decision. ${ }^{15}$ Despite the multidimensionality of the decision, we show that the generalized median voter theorem applies in this context. Hence, we first investigate the preferred policy for any individual, and then address the issue of the political decision itself.

\subsection{The preferred tax policy of agent $i$.}

We now search for the preferred tax policy $\left(\tau_{Y}^{i}, \tau_{E}^{i}\right)$ of agent $i$, when she takes into account her reaction function as a private intertemporal maximizer.

This is obtained by solving the following program:

$$
\begin{aligned}
\max _{\tau_{Y}^{i}, \tau_{E}^{i}} W^{i} & =\int_{0}^{+\infty} e^{-\rho t}\left[\ln \left(c_{i}(t)\right)+V\left(\tau_{E}\right)\right] d t \\
\text { such that } & : \quad c_{i}=\left[\rho+\omega \sigma_{i}(1-\tau)\right] k_{i} .
\end{aligned}
$$

Since $k_{i}$ grows at the rate $\eta$, we know that:

$$
c_{i}=\left[\rho+\omega \sigma_{i}(1-\tau)\right] k_{i}(0) e^{\eta t}
$$

and the program becomes:

$$
\max _{\tau_{Y}, \tau_{E}} W^{i}=\int_{0}^{+\infty} e^{-\rho t}\left[\ln \left(\left[\rho+\omega \sigma_{i}(1-\tau)\right] k_{i}(0) e^{\eta t}\right)+V\left(\tau_{E}\right)\right] d t
$$

Remark that:

$$
\begin{aligned}
W^{i} & =\int_{0}^{+\infty} e^{-\rho t}\left[\ln \left(\rho+\omega \sigma_{i}(1-\tau)\right)+\ln \left(k_{i}(0)\right)+\eta t+V\left(\tau_{E}\right)\right] d t \\
& =\frac{1}{\rho} \ln \left(\rho+\omega \sigma_{i}(1-\tau)\right)+\frac{1}{\rho} \ln \left(k_{i}(0)\right)+\frac{1}{\rho^{2}} \eta+\frac{1}{\rho} V\left(\tau_{E}\right)
\end{aligned}
$$

with $\eta=r(1-\tau)-\rho$. Thus:

$$
\rho W^{i}=\ln \left(\rho+\omega \sigma_{i}(1-\tau)\right)+\ln \left(k_{i}(0)\right)+\frac{r(1-\tau)}{\rho}-1+V\left(\tau_{E}\right)
$$

where $\tau=\tau_{E}+\tau_{Y}, r=\alpha A^{1 / \alpha} \tau_{Y}^{(1-\alpha) / \alpha}, \omega=(1-\alpha) A^{1 / \alpha} \tau_{Y}^{(1-\alpha) / \alpha}=\left(\frac{1-\alpha}{\alpha}\right) r$.

We can prove that there exists an identical linear relationship between the tax rates preferred by any agent $i$ :

Lemma 1 For any agent $i$, her preferred tax rate pair $\left(\tau_{E}^{i}, \tau_{Y}^{i}\right)$ satisfies a unique linear relationship:

$$
\tau_{Y}^{i}+(1-\alpha) \tau_{E}^{i} \cdot=(1-\alpha)
$$

\footnotetext{
${ }^{15}$ Although not its optimality, compared to the solution obtained if the (identical) median voter were allowed to vote sequentially at each period. On this point, see Krusell et al. (1997).
} 
Proof. see Appendix.

According to this lemma, any individual is facing a dilemma between physical goods and the environment. She wishes to save and invest, so as to incur higher future consumption. By the same reasoning, she wants her accumulation effort to be well remunerated. This can be obtained by channeling some public funds obtained from taxation into the production sector and not just in depollution activities. On the whole, this accumulation of capital and this production of goods will deteriorate the environment, relative to its state in a no production, no public policy economy. Hence, the inverse relationship between both taxation ratios reflects the trade-off between future increased consumption and environment quality.

A key feature of this lemma is that there is unanimity on the linear relation (22) between $\tau_{Y}^{i}$ and $\tau_{E}^{i}$ as this relation does not depend on the capital ratio for agent $i$, $\sigma_{i}$, and therefore is identical for any agent $i$. Given (22), the political problem becomes unidimensional and the generalized median voter theorem applies. ${ }^{16}$ Even though the choice is made simultaneously on the joint pair of tax rates, it is as if the two tax rates were chosen sequentially with $\tau_{E}^{i}$ being chosen first and then $\tau_{Y}^{i}$ chosen according to (22). ${ }^{17}$ For a given state of the environment, that is a given $\tau_{E}^{i}$, everybody wants to set $\tau_{Y}^{i}$ so as to maximize the growth rate, which leads to (22). There is no disagreement on this choice. The only debate is therefore on the choice of $\tau_{E}$. This is decided according to the median voter theorem.

Hence, given (22), we can replace $\tau_{Y}$ as a function of $\tau_{E}$, and concentrate on the choice of $\tau_{E} \cdot{ }^{18}$ Then:

$$
r=\alpha A^{1 / \alpha} \tau_{Y}^{(1-\alpha) / \alpha}=\alpha A^{1 / \alpha}\left[(1-\alpha)\left(1-\tau_{E}\right)\right]^{(1-\alpha) / \alpha} .
$$

Given (22) and the definition of $\tau=\tau_{Y}+\tau_{E}$, we immediately get:

$$
1-\tau=\alpha\left(1-\tau_{E}\right) .
$$

Thus, using (23) and (24), we get:

$$
r(1-\tau)=C\left(1-\tau_{E}\right)^{1 / \alpha}
$$

where $C \equiv \alpha^{2} A^{1 / \alpha}(1-\alpha)^{(1-\alpha) / \alpha}>0$. Here $C$ is treated as a constant insofar as it does not depend on the policy instruments.

(21) becomes:

$$
\rho W^{i}=\ln \left(\rho+\left(\frac{1-\alpha}{\alpha}\right) \sigma_{i} C\left(1-\tau_{E}\right)^{1 / \alpha}\right)+\ln \left(k_{i}(0)\right)+\frac{C\left(1-\tau_{E}\right)^{1 / \alpha}}{\rho}-1+V\left(\tau_{E}\right) .
$$

\footnotetext{
${ }^{16}$ A similar reasoning has been applied by Fiaschi (1999) and Kempf and Rossignol (2005).

${ }^{17}$ We could present the sequential moves in reverse order, and reason on the choice of $\tau_{Y}^{i}$ first and then, the choice of $\tau_{E}^{i}$.

${ }^{18}$ We could equivalently express $\tau_{E}^{i}$ as a function of $\tau_{Y}^{i}$ and concentrate on the choice of the latter rate. The same results would obtain.
} 
The environmental policy $\tau_{E}^{i}$ preferred by agent $i$ maximizes $\rho W^{i}$ given by (25). To keep the model analytically tractable, we use the following specification for $V\left(\tau_{E}\right)$ :

$$
\begin{aligned}
& V\left(\tau_{E}\right)=b \frac{\left(\tau_{E}\right)^{1-\lambda}}{1-\lambda}, \lambda \neq 1 \\
& V\left(\tau_{E}\right)=b \ln \left(\tau_{E}\right), \lambda=1
\end{aligned}
$$

where $b>0, \lambda>0$. As $V(\cdot)$ is increasing and concave, an increase in the tax rate $\tau_{E}$ incrases the quality of the environment and therefore welfare, at a decreasing pace. The coefficient $b$ corresponds to the relative weight given to the environment. The higher $b$, the more an agent values the environment, relative to consumption. Given this specification, $\tau_{E}$ has to be positive: we focus on the case where public policy aims at protecting the environment. 19

The following lemma helps us to better understand the trade-off faced by an agent, and will be useful later:

Lemma 2 There exists $\widehat{b}>0$ such that:

if if $b<\widehat{b}$, for any $\sigma_{i}$, the environmental tax $\tau_{E}^{i}$ preferred by agent $i$ is unique, belongs to $\left(0, \widehat{\tau}_{E}\right]$ with $\widehat{\tau}_{E}=\frac{\lambda \alpha}{\lambda \alpha+1-\alpha}<1$ and is decreasing in $\sigma_{i}$;

ii/ if $b>\widehat{b}$, there exists an endowment ratio $\sigma^{*}(b)$ such that any agent $i$ characterized by $\sigma_{i}<\sigma^{*}(b)$ prefers $\tau_{E}^{i}=1$.

Proof. See Appendix.

The case $\tau_{E}=1$ is a corner solution, meaning that the best solution is to stop production. It implies $\tau_{Y}=0, r=\omega=0, G_{E}=\tau_{E} Y=Y=0, c_{i}=\rho k_{i}$. In this case, each agent lives in isolation and consumes over time her own initial endowment. According to the first part of the lemma, there exists a threshold value $\widehat{b}$ for the environment weight, such that for any $b<\widehat{b}$, even the richest individuals want to save and invest for future production at the expense of the environment. When the relative weight given to the environment is low enough, it leads any individual to a compromise between future production and environment quality. Given the properties of the utility function with $b<\widehat{b}$, and a given pair $\left(\tau_{Y}, \tau_{E}\right)$, the less endowed an agent, the higher her marginal utility of physical production. On the other hand, the marginal utility coming from the environment is the same for any agent. Hence the poorer an agent, the less she wants to devote public resources to depollution activities. On the other hand, if $b>\widehat{b}$, at least some agents can be so rich

${ }^{19} \mathrm{~A}$ negative $\tau_{E}$ could be considered using a different specification of the utility function such as

$$
\begin{aligned}
& V\left(\tau_{E}\right)=b \frac{\left(a+\tau_{E}\right)^{1-\lambda}}{1-\lambda}, \lambda \neq 1 \\
& V\left(\tau_{E}\right)=b \ln \left(a+\tau_{E}\right), \lambda=1,
\end{aligned}
$$

where $a$ is positive, with a chosen tax rate superior to $-a$. Results are unchanged when we use this formulation. 
so as to prefer autarky and no production rather than contributing to the degradation of the environment, as a side effect of more physical production. Given her endowment, a relatively rich agent gives a high enough weight to the environment that she prefers to stop production so as to preserve the quality of the environment. Poorer agents prefer an intermediate positive value for $\tau_{E}$ lower than 1 . Remark that when $b<\widehat{b}$, the richer an agent, the higher the overall tax rate she wishes. This comes from the inverse relationship between $\sigma_{i}$ and $\tau_{E}^{i}$, and Lemma $1 .^{20}$

\subsection{The political decision.}

We can now address the issue of the choice of the tax policy when majority rule applies. We assume that no agent, whatever her relative endowment, prefers to stop production, that is $b<\widehat{b}$. This assumption is plausible given the inescapable evidence of productive activities through the world. Given the two previous lemmas, we can state the following:

Proposition 3 i/ The median voter chooses a taxation policy such that $\tau_{E}^{m} \in\left(0, \widehat{\tau}_{E}\right]$ and $\tau_{Y}^{m}=(1-\alpha)\left(1-\tau_{E}^{m}\right)$.

ii/ $\tau_{Y}^{m}$ is an increasing function of $\sigma_{m}$, whereas $\tau_{E}^{m}$ and $\tau^{m}$ are decreasing functions of $\sigma_{m}$, given that $\tau^{m}=\tau_{Y}^{m}+\tau_{E}^{m}$.

Proof. Part i/ directly comes from applying the generalized median voter theorem (Plott, 1967). As for part ii/ of this proposition, we can see $\tau_{E}^{m}$ is a decreasing function of $\sigma_{m}$ since from Lemma $2, \tau_{E}^{i}$ is decreasing in $\sigma_{i}$. The rest follows according to (22) and (24).

Remember that $\sigma_{m}=\frac{\bar{k}}{k_{m}}$ denotes the capital ratio associated with the median voter. Part $i$ / of this proposition states that the median voter is able to decide over fiscal policy. This comes from the fact that there is an unanimous agreement on the linear relationship between the two tax rates and the generalized median theorem can apply. Hence the political decision depends on the ratio $\sigma_{m}$ (see eq.(25)). The ratio $\sigma_{m}$ can be seen as the politically relevant inequality index in this economy. The higher $\sigma_{m}$, the more unequal this economy in a political sense. ${ }^{21}$ Empirically, the plausible case is $\sigma_{m}>1$ (i.e. $k_{m}<\bar{k}$ ). Proposition 3 means that the higher the inequality, the higher $\tau_{Y}^{m}$, and the lower $\tau_{E}^{m}$ and $\tau^{m}$. In a very unequal society, the political decisionmaking process privileges the production $\left(\tau_{Y}\right.$ high) but sacrifices the environment $\left(\tau_{E}\right.$ low). Moreover, given $(22), \tau$ is equal to $(1-\alpha)+\alpha \tau_{E}$. Hence it depends positively on $\tau_{E}$. This explains that $\tau^{m}$ is a decreasing function of $\sigma_{m}$. A poorer agent tends to give higher weight to her material well-being

\footnotetext{
${ }^{20}$ In the case of no concern for the environment $(b=0)$, the solution simplifies to $\tau_{Y}^{i}=(1-\alpha)$ and $\tau_{E}^{i}=0$, for any agent $i$. This is similar to the result obtained by Barro (1990).

${ }^{21} \mathrm{Of}$ course, this index does not capture all dimensions of inequality, and ignore the various moments of the initial capital distribution. The point here is that the political decision hinges on this sole index.
} 
over time, relative to the environment, than a richer one. Consequently, when confronted with the issue of taxing and allocating the proceeds of taxes to either a growing pie or an improved environment, she tends to support both lower taxes and a higher share of the public budget devoted to growth-enhancing expenditures than to toil at the environment. The poorer the median voter (that is, the higher $\sigma_{m}$ ), the lower $\tau$ and $\tau_{E}$. Note that these rates do not depend on the average level of income $\bar{k}$, but only on the inequality ratio $\sigma_{m}$.

Turning to the consequences on growth of this political decision leads to the following:

Corollary 4 The growth rate is an increasing function of $\sigma_{m}$.

Proof. Immediate since the growth rate $\eta$ is equal to $C\left(1-\tau_{E}^{m}\right)^{1 / \alpha}-\rho$

This result directly comes from the property of the growth process. The growth rate is an increasing function of the share of aggregate product used to enhance the technological component $\tau_{Y}$. Hence, the poorer the median voter relative to the average agent, the more she will channel public expenditures to the growth process. Altogether, this corollary claims that in this economy, there is an inverse relationship between the steady-state growth rate and the quality of environment, and that this inverse relationship has its roots in the inequality schedule. This supports the view that it is impossible to disentangle environmental and productive issues because of inequality: agents with different endowments have a different appreciation of the trade-off between physical consumption and the deterioration of the environment over time.

\section{Conclusion}

In this paper, we address the important issue of the long-term impact of income distribution on the environment. We claim that income inequality is harmful for the environment in so far as a concern for a cleaner environment draws public resources away from growthenhancing uses. This trade-off generates a conflict of interest: relatively poor people are more interested in fostering physical growth at the expense of a clean environment whereas relatively rich people are more concerned with the quality of the environment and are more willing to spend for depollution purposes, even if this means a less productive economy in the long run.

This conflict shapes the political debate and generates the main result of the paper: the poorer is the median voter, relatively to the average agent in the economy, the more deteriorated the environment will be, sacrificed to more physical production, that is, higher growth. Of course, this does not contradict the standard result also obtained from the model: a richer (aggregate) society takes better care of the environment than a poorer one as it devotes more aggregate resources $\left(G_{E}\right)$ to environment protection. But here, the 
relative weight given to this aim $\left(G_{E} / Y\right)$ does not depend on the aggregate endowment level of a society but on its distribution.

The model used to obtain the environment is simple. It is based on an AK model of endogenous growth. Other theories of endogenous growth have been offered in the literature, based on human capital, on the growth of good variety, or on R\&D competition. It would be worthwhile to incorporate in these theories some environmental features and see whether they sustain the growth vs environment trade-off we have been able to exploit here. 


\section{Appendix}

\section{A Proof of Lemma 1.}

We search for the pair $\left(\tau_{E}, \tau_{Y}\right)$ maximizing $W^{i}$. This implies to solve the following problem: $\max _{\tau^{E}}\left(\max _{\tau^{Y}}\left(W^{i}\right)\right)=\max _{\tau^{Y}}\left(\max _{\tau^{E}}\left(W^{i}\right)\right)$. Hence, let's fix $\tau_{E}$ and search for the best $\tau_{Y} \cdot{ }^{22}$ For $\tau_{E}$ given, to maximize $W^{i}$ means to maximize $\frac{r(1-\tau)}{\rho}+\ln \left(\rho+\left(\frac{1-\alpha}{\alpha}\right) r(1-\tau) \sigma_{i}\right)$. This is an increasing function of $r(1-\tau)$, thus it is equivalent to search for $\tau_{Y}$ maximizing $r(1-\tau)=r\left(1-\tau_{Y}-\tau_{E}\right)$. We set

$$
f\left(\tau_{Y}\right)=r\left(1-\tau_{Y}-\tau_{E}\right)=\alpha A^{1 / \alpha} \tau_{Y}^{(1-\alpha) / \alpha}\left(1-\tau_{Y}-\tau_{E}\right) .
$$

Derivating this function, we get:

$$
\begin{aligned}
f^{\prime}\left(\tau_{Y}\right) & =\alpha A^{1 / \alpha}\left[\left(\frac{1-\alpha}{\alpha}\right) \tau_{Y}^{\frac{1}{\alpha}-2}(1-\tau)-\tau_{Y}^{(1-\alpha) / \alpha}\right] \\
& =\alpha A^{1 / \alpha} \tau_{Y}^{\frac{1}{\alpha}-2}\left[\left(\frac{1-\alpha}{\alpha}\right)(1-\tau)-\tau_{Y}\right]
\end{aligned}
$$

Therefore:

$$
\begin{aligned}
f^{\prime}\left(\tau_{Y}\right) & \geq 0 \Leftrightarrow \tau_{Y} \leq\left(\frac{1-\alpha}{\alpha}\right)\left(1-\tau_{Y}-\tau_{E}\right) \\
& \Leftrightarrow \alpha \tau_{Y} \leq(1-\alpha)\left(1-\tau_{Y}-\tau_{E}\right) \\
& \Leftrightarrow \quad \tau_{Y} \leq(1-\alpha)\left(1-\tau_{E}\right) .
\end{aligned}
$$

The maximum is attained at $\tau_{Y}$ such that $\tau_{Y}=(1-\alpha)\left(1-\tau_{E}\right)$. We can note that for $\tau_{E}$ given, $\tau_{Y}=(1-\alpha)\left(1-\tau_{E}\right)$ maximizes the growth rate $\eta=r(1-\tau)-\rho$ since it maximizes $r(1-\tau)$.

\section{B Proof of Lemma 2.}

We are looking for $\tau_{E}^{i}$ which maximizes $\rho W^{i}\left(\tau_{E}\right)$, for a given agent $i$. We assume that $\lambda \neq 1$. The proof is similar when $\lambda=1$.

According to (25), we have

$$
\rho W^{i}=\ln \left(1+D_{i}\left(1-\tau_{E}\right)^{1 / \alpha}\right)+\frac{C}{\rho}\left(1-\tau_{E}\right)^{1 / \alpha}+b \frac{\tau_{E}^{1-\lambda}}{1-\lambda}+\text { const }
$$

setting $D_{i} \equiv\left(\frac{1-\alpha}{\alpha}\right) \sigma_{i} \frac{C}{\rho}$.

We introduce the new variable $x=\left(1-\tau_{E}\right)^{1 / \alpha}$ where $\tau_{E} \in[0 ; 1]$ and $x \in[0 ; 1]$.

Let $U_{i}(x) \equiv \ln \left(1+D_{i} x\right)+\frac{C}{\rho} x+b \frac{\left(1-x^{\alpha}\right)^{1-\lambda}}{1-\lambda}$.

It is clear that $\tau_{E}$ maximizes $W^{i}$ on $[0 ; 1]$ if and only if $x$ maximizes $U_{i}(x)$ on $[0 ; 1]$.

\footnotetext{
${ }^{22}$ We could equivalently use the reverse order of maximization.
} 
Let $U_{0}(x) \equiv \frac{C}{\rho} x+b \frac{\left(1-x^{\alpha}\right)^{1-\lambda}}{1-\lambda}$. Then $U_{0}(x)=U_{i}(x)$ for $D_{i}=0$. This corresponds to the case of an infinitely rich agent $i$, when the number of agents is infinite. We deduce:

$$
\begin{aligned}
& U_{0}^{\prime}(x)=\frac{C}{\rho}-b \alpha\left(1-x^{\alpha}\right)^{-\lambda} x^{\alpha-1} \\
& U_{0} "(x)=-b \alpha x^{\alpha-2}\left(1-x^{\alpha}\right)^{-\lambda-1}\left[(\lambda \alpha+1-\alpha) x^{\alpha}-(1-\alpha)\right]
\end{aligned}
$$

and $U_{0} "(x)<0 \Leftrightarrow x>\widehat{x}$ where $\widehat{x}=\left(\frac{1-\alpha}{\lambda \alpha+(1-\alpha)}\right)^{1 / \alpha} \in(0 ; 1)$. Then

$$
U_{0} \text { is convex on }(0 ; \widehat{x}) \text { and concave on }(\widehat{x} ; 1) \text {. }
$$

Before proving Lemma 2, we will first prove that there exists $\widehat{b} \in(0 ;+\infty)$ such that for any $b>0$ :

$$
\begin{aligned}
& b<\widehat{b} \Rightarrow \max _{x \in(0 ; 1]} U_{0}(x)>U_{0}(0) \\
& b>\widehat{b} \Rightarrow \max _{x \in(0 ; 1]} U_{0}(x)<U_{0}(0) .
\end{aligned}
$$

Remark that

$$
\begin{aligned}
U_{0}(x) & <U_{0}(0) \\
& \Leftrightarrow \frac{C}{\rho} x+b \frac{\left(1-x^{\alpha}\right)^{1-\lambda}}{1-\lambda}<\frac{b}{1-\lambda} \\
& \Leftrightarrow \frac{\frac{C}{\rho} x(1-\lambda)}{1-\left(1-x^{\alpha}\right)^{1-\lambda}}<b .
\end{aligned}
$$

Setting $\widehat{b} \equiv \max _{x \in(0 ; 1]} \frac{C}{\rho} x\left[\frac{1-\lambda}{1-\left(1-x^{\alpha}\right)^{1-\lambda}}\right] \in(0 ;+\infty)$, we obtain:

- if $b<\widehat{b}$, there exists $z \in(0 ; 1]$ such that $b<\frac{\frac{C}{\rho} z(1-\lambda)}{1-\left(1-z^{\alpha}\right)^{1-\lambda}}$, i.e. $U_{0}(z)>U_{0}(0)$ and (33) is proved.

- if $b>\widehat{b}$, then $b>\frac{C}{\rho} x\left[\frac{1-\lambda}{1-\left(1-x^{\alpha}\right)^{1-\lambda}}\right]$ for any $x \in(0 ; 1]$, i.e. $U_{0}(0)>U_{0}(x)$ for any $x \in(0 ; 1]$ and $(34)$ is proved.

According to $(32), U_{0}^{\prime}$ is increasing on $(0 ; \widehat{x})$ and decreasing on $(\widehat{x} ; 1)$. Since $\lim _{x \rightarrow 0} U_{0}^{\prime}(x)=$ $-\infty$ and $\lim _{x \rightarrow 1} U_{0}^{\prime}(x)=-\infty$ two cases are possible:

$(I)$ if $U_{0}^{\prime}(\widehat{x}) \leq 0$ then $U_{0}^{\prime}(x) \leq 0$ for every $x \in(0 ; 1)$;

$(I I)$ if $U_{0}^{\prime}(\widehat{x})>0$ then there exist $x_{0}$ and $y_{0}$ such that:

$0<y_{0}<\widehat{x}<x_{0}<1$ and: $U_{0}^{\prime}(x)>0$ for $x \in\left(y_{0} ; x_{0}\right)$ and $U_{0}^{\prime}(x)<0$ for $x \notin\left[y_{0} ; x_{0}\right]$.

We will now prove Lemma 2.

A/ Suppose that $b<\widehat{b}$. According to $(33), U_{0}^{\prime}$ is not always negative on $(0 ; 1)$, so $(I I)$ is true. Finally, we have found $x_{0} \in(\widehat{x} ; 1)$ such that $U_{0}\left(x_{0}\right)>U_{0}(x)$ for any $x \in[0 ; 1]$ with $x \neq x_{0}$.

Similarly, we want to prove that for $D_{i}>0$, there exists $x_{i} \in(\widehat{x} ; 1)$ such that $U_{i}\left(x_{i}\right)>$ $U_{i}(x)$ for any $x \in[0 ; 1]$ with $x \neq x_{i}$. If $x \leq \widehat{x}<x_{0}, U_{i}(x)=U_{0}(x)+\ln \left(1+D_{i} x\right)<$ $U_{0}\left(x_{0}\right)+\ln \left(1+D_{i} x_{0}\right)=U_{i}\left(x_{0}\right)$ because $U_{0}(x)<U_{0}\left(x_{0}\right)$ and $\ln \left(1+D_{i} x\right)<\ln \left(1+D_{i} x_{0}\right)$ since $D_{i}>0$. Hence, $\max _{x \in[0 ; \widehat{x}]} U_{i}(x)<\max _{x \in[0 ; 1]} U_{i}(x)$ 
Since $U_{i} "(x)=U_{0} "(x)-\frac{D_{i}^{2}}{\left(1+D_{i} x\right)^{2}}$ with $U_{0}$ concave on $(\widehat{x} ; 1)$, then $U_{i}$ is concave on this interval too, and finally the maximum of $U_{i}$ on $[0 ; 1]$ is attained at a unique point $x_{i}$, and $x_{i} \in(\widehat{x} ; 1)$.

Let us show that $x_{i}$ is an increasing function of $D_{i}$. Assume that $0<D_{i}<D_{j}$.

If $x<x_{i}$ then $U_{j}(x)=U_{i}(x)+\ln \left(\frac{1+D_{j} x}{1+D_{i} x}\right)<U_{i}\left(x_{i}\right)+\ln \left(\frac{1+D_{j} x_{i}}{1+D_{i} x_{i}}\right)=U_{j}\left(x_{i}\right)$ because $U_{i}(x)<U_{i}\left(x_{i}\right)$ and $\ln \left(\frac{1+D_{j} x}{1+D_{i} x}\right) \leq \ln \left(\frac{1+D_{j} x_{i}}{1+D_{i} x_{i}}\right)$. Hence, $\max _{x \in\left[0 ; x_{i}\right)} U_{j}(x)<\max _{x \in[0 ; 1]} U_{j}(x)$, which implies that $x_{i} \leq x_{j}$.

Remark that $U_{j}^{\prime}(x)=\frac{D_{j}}{1+D_{j} x}-\frac{D_{i}}{1+D_{i} x}+U_{i}^{\prime}(x)$, and $U_{i}^{\prime}\left(x_{i}\right)=0$ since $U_{i}$ is maximum at $x_{i}$. Then, we have $U_{j}^{\prime}\left(x_{i}\right)=\frac{D_{j}}{1+D_{j} x_{i}}-\frac{D_{i}}{1+D_{i} x_{i}}>0$. We conclude that $x_{i}<x_{j}$.

We have thus proven that, if $b<\widehat{b}$, for any $D_{i}>0$, there is a unique $x_{i}$ which maximizes $U_{i}(x)$ on $[0 ; 1]$, and that $x_{i} \in(\widehat{x} ; 1), x_{i}$ is an increasing function of $D_{i}$. According to our change of variables, it means that Lemma 2 (i) is proven, with $\tau_{E}^{i}=1-x_{i}^{\alpha}$, and $\widehat{\tau}_{E}=1-\widehat{x}^{\alpha}=1-\frac{1-\alpha}{\lambda \alpha+(1-\alpha)}=\frac{\lambda \alpha}{\lambda \alpha+(1-\alpha)}$

B/ Suppose that $b>\widehat{b}$. According to $(34), U_{0}(x)<U_{0}(0)$ for any $x \in(0 ; 1]$. For $D_{i}$ small enough, we will have: $\forall x \in(0 ; 1], U_{i}(x)=U_{0}(x)+\ln \left(1+D_{i} x\right)<U_{0}(0)=U_{i}(0)$. It means that Lemma 2 (ii) is proven with $\tau_{E}^{i}=1-x_{i}^{\alpha}=1$, since here $x_{i}=0$, for $D_{i}$ small enough.

\section{References}

[1] Aghion, P., E. Caroli and C. Garcia-Penalosa [1999], "Inequality and economic growth: the perspective of the new growth theory", Journal of Economic Literature, vol. 37, 1615-1660.

[2] Alesina A. and D. Rodrik [1994], "Distributive politics and economic growth", Quarterly Journal of Economics, vol. 109, 465-490.

[3] Andreoni J. and A. Levinson [2001], "The simple analytics of the environmental Kuznets curve", Journal of Public Economics, vol. 80, 269-286.

[4] Barro R. [1990], "Government spending in a simple model of endogenous growth", Journal of Political Economy, vol. 98, S103-S125.

[5] Earnhart D. [1997], "Enforcement of environmental protection laws under communism and democracy", Journal of Law and Economics, vol. 40, 377-402.

[6] Fiaschi D. [1999], "Growth and inequality in an endogenous fiscal policy model with taxes on labor and capital", European Journal of Political Economy, vol. 15, 727-746.

[7] Holtz-Eakin D. and T. M. Selden [1995], "Stocking the fires? $\mathrm{CO}_{2}$ emissions and economic growth", Journal of Public Economics, vol. 57, 85-101. 
[8] Jones L. R. and R. Manuelli [2001], "Endogenous policy choice: the case of pollution and growth", Review of Economic Dynamics, vol. 4, 369-405.

[9] Kahn M. E. and J. G. Matsusaka [1997], "Demand for environmental goods: evidence from voting patterns on California initiatives", Journal of Law and Economics, vol. 40, 137-173.

[10] Kempf H. and S. Rossignol [2005], "Growth, inequality and integration: a political economy analysis", Journal of Public Economic Theory.

[11] Krusell P., V. Quadrini and J.-R. Rios-Rull [1997], "Politico-economic equilibrium and economic growth", Journal of Economic Dynamics and Control, vol. 21, 243-272.

[12] Magnani E. [2000], "The environmental Kuznets Curve, environmental protection policy and income distribution", Ecological Economics, vol. 32, 431-443.

[13] Marsiliani L. and T. Renström [2000], "Inequality, environmental protection and growth", Center of Economic Research working paper 2000-34.

[14] Marrewijk, C. van der, F. van der Ploeg and J. Verbeek [1993], "Is growth bad for the environment?", The World Bank, Policy Research Working Papers WPS 1151.

[15] Meltzer A. and S. Richard [1981], "A rational theory of the size of government", Journal of Political Economy, vol. 89, 914-927.

[16] Perotti R. [1996], "Growth, income distribution and democracy: what the data say," Journal of Economic Growth, vol. 1, 149-187.

[17] Plott C.R. [1967], "A notion of equilibrium and its possibility under majority rule", American Economic Review, vol. 57, 786-806.

[18] Roberts K. [1977], "Voting over income tax schedules", Journal of Public Economics, vol. 8, 329-340.

[19] Smulders S. [1999], "Economic growth and environmental quality", chapter 20, Environmental Economics, edited by H. Folmer and L. Gabel, Edward Elgar.

[20] Torras, M. and J.K. Boyce [1998], "Income inequality and pollution: a reassement of the environmental Kuznets curve", Ecological Economics, vol. 25, 147-160 